\title{
Condition Assessment of Oil Transformer Insulating System
}

\author{
P. $\operatorname{Prosr}^{1}$, M. Brandt' ${ }^{2}$ V. Mentlík ${ }^{1}$, J. Michalík ${ }^{3}$, \\ ${ }^{1}$ University of West Bohemia, \\ Faculty of Electrical Engineering, Department of Technologies and Measurement, \\ Univerzitní 26, 30614 Pilsen (Czech Republic) \\ Phone/Fax number: +420 377634 519/ +420 377634 502, e-mail: prosr@ket.zcu.cz \\ ${ }^{2}$ University of Žilina \\ Faculty of Electrical Engineering, Department of Measurement and Applied Electrical Engineering \\ Univerzitná 1, 01026 Žilina, Slovakia \\ Phone/Fax number: +421 41513 5063/+421 415131529 brandt@fel.uniza.sk \\ ${ }^{3}$ Research Centre of Mechatronics Systems \\ EVPÚ a.s. Nová Dubnica and Faculty of Electrical Engineering ŽU in Žilina \\ Univerzitná 1, 01026 Žilina (Slovakia) \\ Phone/Fax number: +421 41513 5063/+421 41513 1529, e-mail: michalik@ fel.uniza.sk
}

\begin{abstract}
Reliable operation of transformers largely depends on a lifetime of insulating system. For this reason the paper deals with a description of our experience with developed monitoring system, which is focused mainly on a control of oil filling of experimental transformer. Relative humidity, amount of dissolved gases and increased temperature are observed, as they have decisive influence on insulating system of transformer. Monitoring of these characteristics is completed with analysis of oil samples by infrared spectroscopy in mode of Attenuated Total Reflection technique.
\end{abstract}

\section{Key words}

Monitoring system, transformer, infrared spectroscopy, gas chromatography

\section{Introduction}

Action of degradation parameters such as increased humidity or temperature presents serious threat for service life of transformer with oil-paper insulating system. While increased temperature accelerates deterioration of insulating system in a large extent, humidity causes mainly the deterioration of electrical parameters [1-3]. Provision of failure-free operation of all essential parts of manufacturing process is the basic demand of every operator. In case of transmission and distribution system, the transformer is one of the key elements; hence the on-line diagnostic system has been designed to assess the condition and loading mode of transformers. [4] The objective of the paper is to extend our experience with this system and extend the assessment methods of properties of, in particular, oil filling.

\section{Parts of transformer and monitored parameters}

Simplified look on transformer construction shows the four basic subsystems of transformer, as described bellow, whereas the first two of them are referred to as the transformer active part:

1. Core/winding - provide current passage through the primary and secondary windings, these parts also help to create the magnetic flux that gradually generates the magnetic field.

2. Magnetic circuit - enables to transfer the magnetic field generated by primary winding to the secondary winding.

3. Transformer vessel - serves as a mechanical cover to protect the active part of transformer, it also serves as a vessel for transformer oil, which carries out the insulating and cooling functions.

4. Insulating system - key subsystem of transformer. Since it is largely influenced by operational and degradation characteristics, it is considered the weakest piece of the whole transformer. It consists of winding insulation, cylinder made from transformer paper and oil.

From the on-line monitoring point of view, it is preferable to monitor mainly the active part of transformer. The current passage through the winding causes the warming of the conductors. This warming increases with increasing loading and conductors then warm also the insulation and contribute to its higher degradation (thermal aging of paper-oil insulation systems was mathematically described by Montsinger). [5], [6]

It is useful to focus on measurement of temperature of winding in case of monitoring of thermal stress of the insulation, as the temperature of winding is always higher 
than the temperature of oil filling and causes then more degradation. It is possible to compare the temperature of winding to courses of loading currents and voltages of single phases of transformer. The measurement of operation voltages and currents enables to obtain the characteristics necessary for assessment of instantaneous loading of transformer. Loading current moreover influences the quantity of Joule losses in the winding, hence its assessment allows the estimation of thermal loading of transformer insulating system.

Amount of gases dissolved in transformer oil is another important characteristics which helps to identify a contingent failure. Gas analysis provides the first information on appearance of failure in transformer and allows its detection in the early stage. [7]

\section{Experimental diagnostic laboratory}

Two distribution transformers (supply T2 transformer and experimental $\mathrm{T} 1$ transformer) are part of the experimental laboratory. Transformers have following characteristics:

T1: BEZ kTO 253/22, no. Bra 42931, MY 1958, 30 kVA, Yz1, 23100/22000/20900 V/ 400/230 V, uk $=4,96 \%$, 0,787 A / 43,3 A

and T2: BEZ aT 0294/22, no. 231279, MY 1983, 100

kVA, Yzn1, 22000 $\pm 2 * 2,5 \% \mathrm{~V} / 400 / 230 \mathrm{~V}, \mathrm{uk}=3,96 \%$, 2,62 A / 144,4 A.

Via Lovato DMK 20 electronic industrial multimeter, monitoring system put into operation on experimental distribution transformer under laboratory conditions measures operation characteristics such as U, I, P, S, Q, etc., it measures temperature of winding (via NEOPTIX optical fibre probes) and it also monitors single trends of total amount of gases dissolved in transformer oil as well as humidity and water level (Hydran M2 sensor). The temperature of oil in the upper part of transformer vessel (PTP 50) has been being measured since 3.10. 2008. Following figure (Fig. 1) presents the functional block diagram of designed monitoring system of transformer.

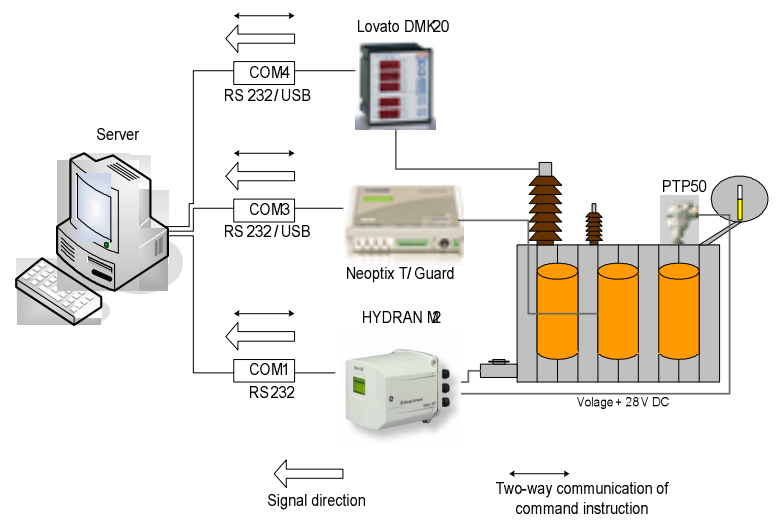

Fig. 1. Functional block diagram of designed monitoring system The monitoring system results are completed with the analysis of oil samples taken gradually along the transformer operation at the common loading as well as along the operation at increased action of significant characteristics (temperature, loading...). Analysis of oil samples by gas chromatography and infrared spectroscopy has been chosen as additional methods.

\section{Results of monitored characteristics}

Transformer was loaded by resistance-inductive loading along its operation. This loading was created by resistors of $10 \Omega$ in the phase and asynchronous motor with the power of $15 \mathrm{~kW}$. Both of these loadings present approx. $50 \%$ of rated $\mathrm{kVA}$ of experimental transformer power. Figure 2 illustrates the active and apparent powers measured in the transformer output in the time interval from 8.12. 2008 to 27.6. 2009.

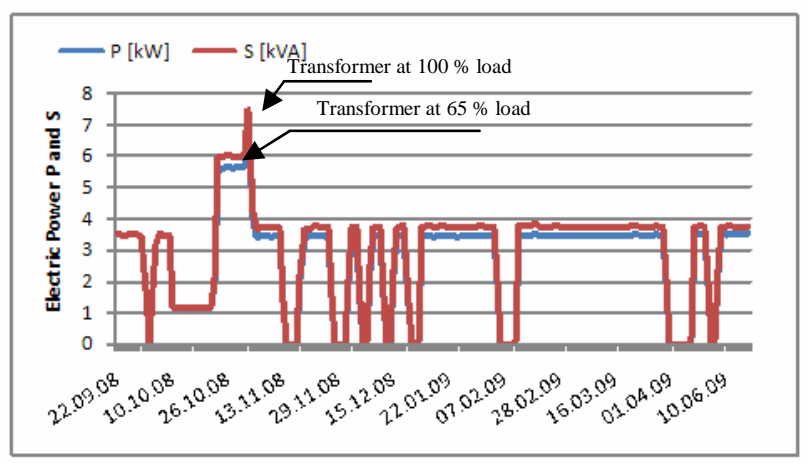

Fig. 2. Powers of transformer loading

Many changes have been made in the way of loading since the first experimental transformer start-up, which led to deterioration of insulating oil condition (becoming evident as excessive increase of gas amount and humidity level at slightest load increase - see Fig. 3). Changes of mechanical configuration of winding could be the probable cause of mentioned experimental transformer gassing. These changes refer to bigger mechanical drift of winding towards the transformer core, which has been already confirmed by Sweep Frequency Response Analysis (SFRA). [4] Gas creation in transformer oil is also influenced by the humidity that leaks to the transformer insulating system during its demounting.

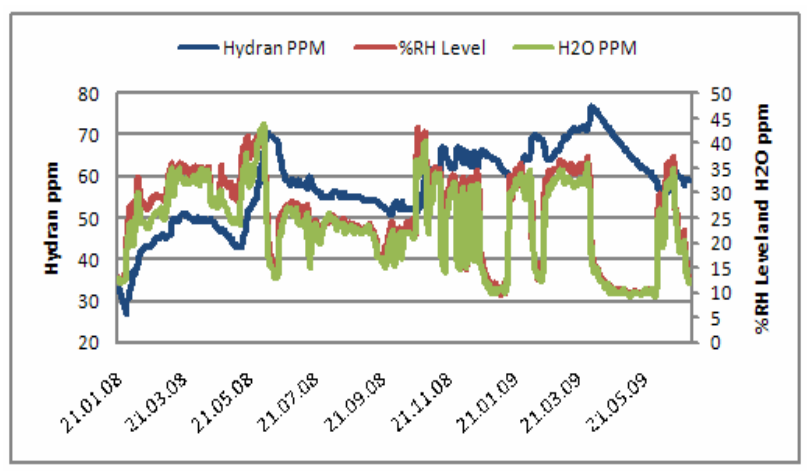

Fig. 3. Courses of gas content and humidity level in oil from 21.1.2008 to 4.7.2009

Trend of total amount of gases (Hydran PPM) is directly connected with the changes of loading. As Figures 2 and 3 show, changes of loading cause expressive change in amount of dissolved gases. Decrease of loading leads to decrease of gas amount with some time delay. Level of water $(\mathrm{ppm})$ and relative humidity $(\% \mathrm{RH})$ in the oil is influenced by the changes of loading very similarly - see Fig. 3.

As we can see in Fig. 4, responses of $\mathrm{RH}$ and $\mathrm{H} 2 \mathrm{O}$ on changes of temperatures of winding (TW) are faster than changes of gas amount. 


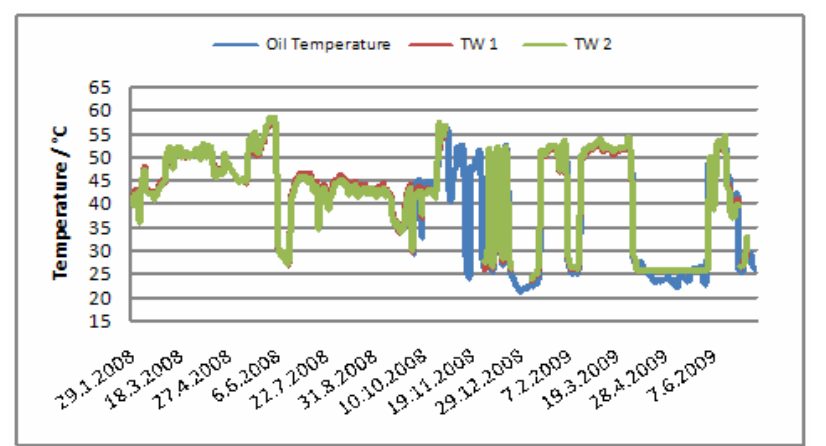

Fig. 4. Oil temperature and temperature of winding in measurement interval from 29.1.2008 to 4.7. 2009

Level of humidity in the oil copies the curve of temperature of winding quite precisely. The temperature of winding is recorded by two NEOPTIX T2 sensors, which are installed in the upper part of transformer and in the middle of primary winding of the middle phase.

When compared the temperature of winding and oil temperature in the upper part of transformer vessel, their curves are also very similar, as shown in Fig. 5. The temperature decreases with decreasing loading with a little time delay, whereas the temperature of winding is almost always higher than the oil temperature. This is most likely caused by higher cooling intensity of oil (through the vessel walls) compared to the winding that is cooled down only thanks to the cooling oil.

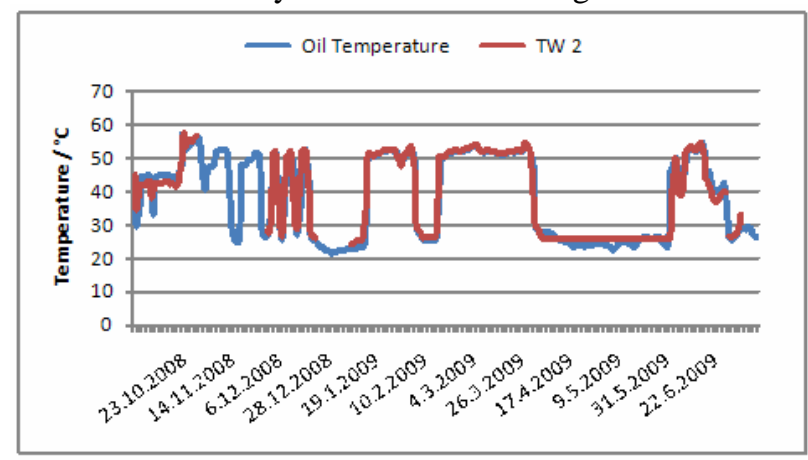

Fig. 5. Winding and oil temperature in measurement interval from 3.10.2008 to 4.7.2009

\section{Infrared spectroscopy (FT-IR-ATR)}

Fourier Transform Infrared Spectroscopy in the mode of Attenuated Total Reflection technique (ATR) has been chosen as another additional method of assessment of oil filling condition.

This method is based on the principle of multiple total reflection of radiation on the phase measured samplemeasuring crystal interface (crystal made from material of high index of refraction) - see Fig. 6. Technique of Attenuated Total Reflectance (ATR) is very suitable especially for measuring of spectra of liquid samples intensely absorbing the infrared radiation.

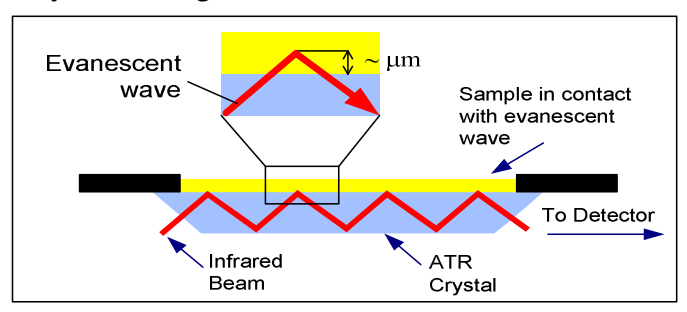

Fig. 6. Principle of Attenuated Total Reflectance
Every time, when infrared ray is reflected inside the crystal, certain portion of radiation (so called evanescent wave) exceeds the crystal-sample interface and enters the sample, which results in its absorption in the sample. When the monitored sample absorbs the radiation of specific frequency, this portion is attenuated in totally reflected light. The spectral display of characteristic bands is the result of this analysis. This display is largely similar to spectrum obtained in transmittance mode [911]. Level of degradation is possible to assess on the basis of comparison of obtained spectra. Change of intensity of characteristic bands or appearance of completely new band in case of the same material eventually refers to the level of aging.

Measurements were performed via Nicolet 380 spectrometer in connection with Smart MIRacle ATR cell (ZnSe crystal). 32 scans were collected at resolution of $4 \mathrm{~cm}^{-1}$ for all spectra measuring. OMNIC software was consequently used for display and analysis of collected spectra.

Samples of virgin oil, sample of oil taken along the transformer operation (operational oil - May 2009), sample of sediment taken from the bottom of transformer vessel and sample of oil taken from the cool transformer after its shutdown (shutdown oil - December 2009) were measured. Obtained spectra are illustrated in Figure 7. Final spectrum is formed of the average value of three separate measurements.

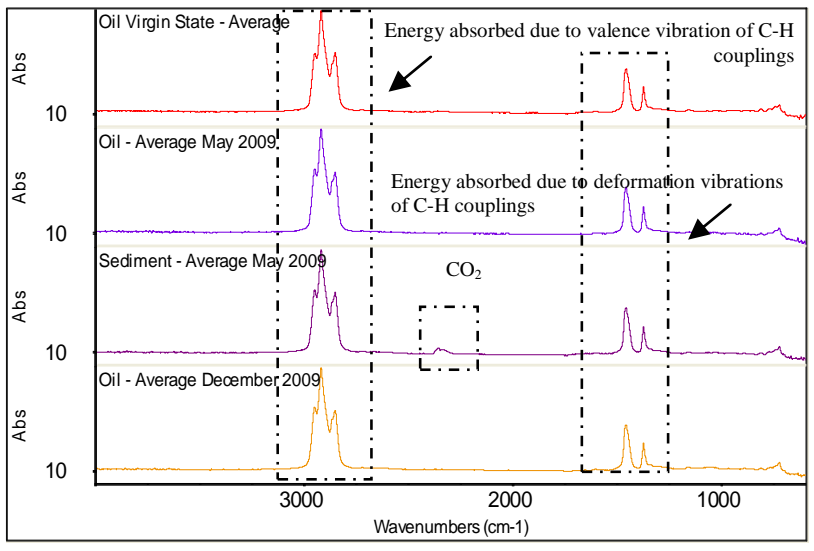

Fig. 7 Spectra of experimental transformer oil.(virgin state, operational oil, sediment, shutdown oil)

As shown in Fig. 7, no significant changes of neither virgin oil spectrum nor spectra of samples from experimental transformer vessel (oils from May and December) have been observed yet (mainly in the area of additives in the range of $\left.1360-790 \mathrm{~cm}^{-1}\right)$. In comparison to previous, sediment spectrum contains a band of $2358 \mathrm{~cm}^{-1}$ corresponding to carbon dioxide, which is one of the decomposition products during the degradation of solid component of insulating system.

Obtained spectra can be divided into two basic groups 1) so called region of valence vibrations, where mostly absorption bands of functional groups occur (4000 $1500 \mathrm{~cm}^{-1}$ ) and 2) region of deformation vibrations (so called finger print region $-1500-500 \mathrm{~cm}^{-1}$ ).

Dominant bands in the region of functional groups correspond to the energy absorbed due to valence vibration of $\mathrm{C}-\mathrm{H}$ couplings $(\mathrm{CH} 2$ and $\mathrm{CH} 3$ couplings 2921 and $2853 \mathrm{~cm}^{-1}$ concretely). In the finger print region 
the bands correspond to the energy absorbed due to deformation vibrations of C-H couplings. Slight band of $723 \mathrm{~cm}^{-1}$ then corresponds to out-of-plane deformation vibration of $\mathrm{CH}$ group.

Assessment of influence of aging process by FT-IR ATR is possible on the basis of comparison of interactive reading of spectral bands of 1457 and $1376 \mathrm{~cm}^{-1}$, which should be constant (see Fig. 8). Spectra of above mentioned oil samples are compared.

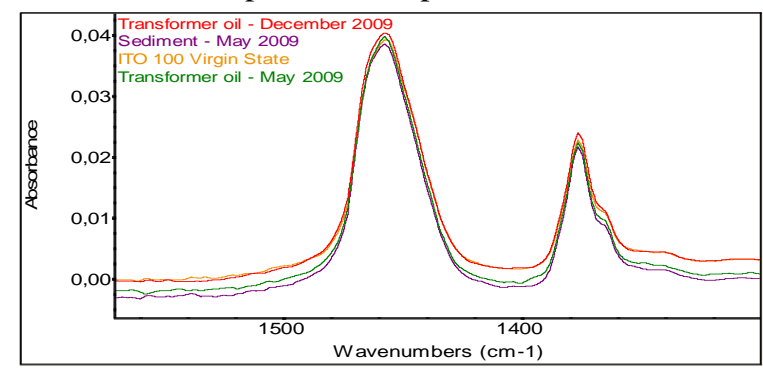

Fig. 8.Detailed display of $1550-1300 \mathrm{~cm}^{-1}$ region

Specific changes in spectra, which can point to the transformer failure are obvious from Figure 8. While the spectrum of operational oil is expressively close to spectrum of sediment sample, the shutdown oil spectrum almost overlaps with spectrum of virgin oil. This could mean certain reversible change that occurs during the transformer operation compared to expected process.

\section{Gas chromatography (DGA) results}

Another additional method of oil condition assessment is Dissolved Gas Analysis. DGA is one of the most important instruments for detection of transformer oil filling condition. The presence of increased amount of single gases $/ \mathrm{ppm} /$ refers to probable abnormal behaviour of machine and enables operator to take necessary steps to prevent the machine failure.

Gas chromatography was carried out via Kelman Transport $\mathrm{X}$ device. Initial parameters were $\mathrm{H}_{2}=26 \mathrm{ppm}$, $\mathrm{H}_{2} \mathrm{O}=25 \mathrm{ppm}, \mathrm{RH}=15 \%$. Comparing the Hydran sensor results, no expressive difference was observed (composite value of gas amount of $29 \mathrm{ppm}$, humidity of $14,2 \%$ level and water of $12 \mathrm{ppm}$ ).

Gas chromatography also provided following gas concentrations: $\mathrm{CO}_{2}=1290 \mathrm{ppm}, \mathrm{CO}=96 \mathrm{ppm}, \mathrm{C}_{2} \mathrm{H}_{4}=$ $19 \mathrm{ppm}, \mathrm{C}_{2} \mathrm{H}_{6}=5 \mathrm{ppm}, \mathrm{CH}_{4}=5 \mathrm{ppm}$.

In operation, there is highly recommended to perform the demanded measurements in predefined intervals. We perform those measurements whenever any more significant intervention to transformer body is done. Therefore the next analysis of dissolved gases is scheduled for the time after the experimental transformer revision.

\section{Conclusion}

Detailed knowledge of operation state of transformer is required as one of the fundamental conditions of electric power network operation. This knowledge enables also transformer operation with minimum risk of unexpected failure.

Many special ways of machine working (loading mode, frequent shut downs and start ups of transformer etc.) were performed along the time of experimental transformer operation. Some changes in transformer occurred as a result of such approach. Mentioned diagnostic methods help to identify these changes. Therein application of Gas Chromatography is considered the most significant together with the results of gas products analysis via Hydran M2 sensor. Observed trends are completed with infrared spectroscopy, which also supports the assessment of oil filling condition.

Since this monitoring system has already helped to detect the changes (winding drift etc.) and on-coming failure of experimental transformer [4], it is planned to remove it to the distribution transformer operated by Stredoslovenska energetika a.s. It is failure transformer on which SFRA (Sweep Frequency Response Analysis) measurement as well as oil sampling and analysis has being done regularly.

\section{Acknowledgement}

This article was carried out with the support of Ministry of Education, Youth and Sports of Czech Republic, MSM 4977751310 - Diagnostics of Interactive Processes in Electrical Engineering and R\&D operational program Centre of excellence of power electronics systems and materials for their components No. OPVaV-2008/2.1/01SORO, ITMS 26220120003 funded by European regional development fund (ERDF).

\section{References}

[1] T. K. Saha, "Review of modern diagnostic techniques for assessing insulation condition in aged transformers", IEEE Transactions on Dielectrics and Electrical Insulation. Vol. 10, pp. 903-917, 2003.

[2] K. Najdenkoski, G. Rafajlovski, V. Dimcev, "Thermal Aging of Distribution Transformers"

[3] Reigh Walling, G. Bruce Shattuck Distribution transformer thermal behavior and aging in local-delivery distribution systems, 19th International Conference on Electricity Distribution, Vienna, 2007, Paper N. 0720

[4] Mentlík, Václav, aj. Instruments for On-line Monitoring of Transformers. INTERNATIONAL CONFERENCE ON RENEWABLE ENERGIES AND POWER QUALITY, 2009.

[5] V.M. Montsinger "Loading transformer by temperature" AIEE transactions, Bd. 49, 1930, p. 776-792.

[6] Brancato E. L. A pathway to Multifactor Aging, IEEE Transaction on Electrical Insulation, Vol. 28 No. 5, October 1993.

[7] Piush Verma Condition monitoring of transformer oil and paper, doctor thesis Patiala, India, 2005.

[8] FT-IR Spectroscopy Attenuated Total Reflectance (ATR) PerkinElmer technical note http://las.perkinelmer.com/.

[9] Trchová, M. Jak vibrují atomy v molekulách. In Otevřená věda : Praktické kurzy z fyziky a chemie. [s.l.] : [s.n.], 2006. Dostupný z WWW: <http://www.otevrenaveda.cz/ov/index.php?p=kurzy>.

[10] Fahrenfort J.: Spectrochim. Acta 17, 698 (1961).

[11] J. Hájek, V. Machovič, O. Křížová, V. Sedláčková, M. Novotná, "Využití infračervené spektrofotometrie pro sledování změn při oxidaci řepkového oleje“. Chem. Listy 92, 434 - 440 (1998). 